\title{
Caminhos do desenvolvimento profissional docente na perspectiva freireana
}

Lilian Moreira Cruz

Andreia Cristina Freitas Barreto

Lúcia Gracia Ferreira

\section{Resumo}

O presente artigo objetiva discutir possibilidades de caminhos do Desenvolvimento Profissional Docente (DPD) na perspectiva freireana, tendo como aporte o livro "Medo e ousadia: o cotidiano do professor". Paulo Freire é tomado neste estudo como possibilidade de rompimento paradigmático que, na atualidade, é oportuno, sobretudo, no Brasil, país que atravessa um momento de severas críticas sobre os profissionais da educação, pois estes vêm sofrendo retaliações em sua autonomia, formação e prática docente, o que, consequentemente, vem provocando, muitas vezes, rupturas no DPD. Diante desses desafios vividos pelos/as professores/as, faz-se necessário reinventar o pensamento de Paulo Freire para provocar problematizações e reflexões sobre os possíveis caminhos para o Desenvolvimento Profissional Docente. Desse modo, fizemos uma revisão do livro citado, apontando possibilidades de contribuições da perspectiva freireana para o DPD, a partir da formação, do currículo, do ensino e da relação do professor/a com o conhecimento. Com isso, constatamos que Freire muito contribuiu para os estudos sobre o DPD, apontando possíveis caminhos para a evolução e continuidade desse processo.

Palavras-chaves: Desenvolvimento Profissional Docente. Paulo Freire. Formação. 


\title{
Paths of teaching professional development in freire's perspective
}

\author{
Lilian Moreira Cruz \\ Andreia Cristina Freitas Barreto \\ Lúcia Gracia Ferreira
}

\section{Abstract}

This article aims to discuss possibilities of paths of Teacher Professional Development (DPD) in Freire's perspective, based on the book "Fear and boldness: the teacher's daily life". Paulo Freire is taken in this study as a possibility of paradigmatic disruption that is currently appropriate, especially in Brazil, a country that is going through a moment of severe criticism about education professionals, because they have been suffering retaliation in their autonomy, training and practice. which, consequently, has often caused disruptions in the DPD. Given these challenges experienced by teachers, it is necessary to reinvent Paulo Freire's thinking in order to provoke problematization and reflections on the possible paths for Teacher Professional Development. Thus, we made a review of the book cited, pointing possibilities of contributions from the Freire perspective to DPD, from the formation, the curriculum, the teaching and the relationship of the teacher with knowledge. With this, we found that Freire contributed a lot to the studies on DPD, pointing out possible ways for the evolution and continuity of this process.

Keywords: Teacher Professional Development. Paulo Freire. Training. 


\section{Introdução}

Nos dias atuais, o Desenvolvimento Profissional Docente (DPD) tem ganhado destaque nas discussões acadêmicas, pois é um campo de investigação necessário, uma vez que abrange o/a professor/a em vários aspectos, como a formação (inicial e continuada), atuação profissional, condições de trabalho, valorização e carreira docente, entre outros. Não dá para estudar o DPD sem pensar nesses aspectos, bem como o contexto político em que os/as professores/as estão inseridos/as, porquanto afetamos e somos afetados pela conjuntura social. Destarte, Paulo Freire é um teórico que nos provoca a refletir sobre estas questões, bem como o desdobramento da politicidade da educação e seus reflexos na vida e atuação dos/as docentes.

Embora Paulo Freire não tenha tido o DPD como tema de debate em suas obras, suas discussões, nos mais variados livros, perpassam reflexões sobre os aspectos que englobam o DPD, especialmente nos livros: "Medo e ousadia: o cotidiano do professor" (2008); "Professora sim, tia não: cartas a quem ousa ensinar" (1993b); "A educação na cidade" (2001); "Política e Educação" (1993); "Pedagogia da autonomia: saberes necessários à prática docente” (1996). Pela complexidade do seu pensamento, tomamos como aporte neste artigo a obra "Medo e ousadia: o cotidiano do professor" (FREIRE; SHOR, 2008) para discutir os caminhos do desenvolvimento profissional docente.

Paulo Freire nos legou uma filosofia de vida e uma teoria do conhecimento. Ele foi um ícone que extrapolou o Brasil e ganhou o mundo. Esse lugar que ele ocupa na educação é resultado da sua militância por uma educação pública de qualidade para todos/as. Assim, trazer Paulo Freire para o cerne das nossas discussões é pensar o futuro da educação brasileira, é reinventá-lo num campo novo de conhecimento, ou seja, no campo do DPD.

No contexto atual da situação política do Brasil, é preciso tomar o pensamento de Paulo Freire para discutir o papel do/a professor/a e esse artigo nos ajudará nessa tarefa. Vivemos tempos de intenso fracasso escolar, nos mais variados níveis de ensino, precisamos reverter essa situação com amorosidade, com sabedoria para assumir a politicidade da educação fora da cegueira partidária e assumir o real papel da educação - ofertar uma formação equitativa.

Propomo-nos, neste artigo, pensar abertamente o que está em "jogo" no DPD e seus reflexos na tarefa de ensinar, pois o século XXI requer dos/das professores/as postura crítica diante de seu próprio crescimento profissional para garantir a sua autonomia e condições de trabalho e, especialmente, para que se desenvolvam profissionalmente. É dessa forma que pode colaborar para uma educação humanizadora e emancipatória.

O DPD abarca a perspectiva de evolução e continuidade, abrange tanto a formação inicial e continuada como também outros aspectos - contextos individuais e coletivos, contexto pessoal, social, cultural, profissional, entre outros. Desse modo, os caminhos do DPD cruzam 
com várias perspectivas teóricas, sendo uma delas a freireana. Assim, este artigo objetiva realizar reflexões teóricas sobre a temática e sua relação com a escolha teórica para realizar relação.

\section{Desenvolvimento profissional docente: o cotidiano do professor}

O livro "Medo e ousadia: o cotidiano do professor" é resultado de um diálogo entre dois educadores, Paulo Freire e Ira Shor, ocorrido em Vancouver, no Canadá, em 1986. Os encontros dos autores ocorreram durante oito dias, com duração de três horas de gravação diariamente (FREIRE; SHOR, 2008). Os diálogos tecidos por eles apresentam uma fecunda discussão sobre o cotidiano do/a professor/a, o que possibilitou discutir os caminhos do DPD neste artigo. Entendemos o DPD na perspectiva de Marcelo Garcia (1999) e Day (2001), que o defendem como um processo que é contínuo, individual e/ou coletivo, que se concretiza no local de trabalho docente e atravessa toda a trajetória do/a professor/a no campo profissional.

Na obra, Freire e Shor (2008) apresentam alguns questionamentos para direcionar os seus diálogos, como por exemplo:

O que é o ensino libertador? Como é que os professores se transformam em professores libertadores? Como é que começam a transformar os estudantes? Quais os temores, os riscos e as recompensas da transformação? O que é o ensino dialógico? Como deve os professores falar num discurso libertador? Uma classe libertadora tem rigor, autoridade e estrutura? Os professores e os alunos são iguais num programa libertador? De que modo a educação libertadora se relaciona com a transformação política, dentro da sociedade como um todo? Este processo pode ser aplicado em outros cursos, além dos de alfabetização e comunicação? Como se pode transmitir conteúdos através de um método de diálogo? Como os professores libertadores utilizam as provas e os textos? O que quer dizer empowerment*? Podemos aplicar no Primeiro Mundo uma pedagogia do Terceiro Mundo? Como os temas raça, sexo e classe se enquadram no processo libertador? (FREIRE; SHOR, 2008, p. 11).

Essas questões são norteadoras das discussões trazidas no livro, o que nos leva a acreditar que Shor e Freire colocaram o/a professor/a como protagonista da educação e do seu DPD. De acordo os autores, o objetivo do livro foi tecer um diálogo em torno da Educação como prática de libertação ou transformação social, a partir da teoria e da prática de uma pedagogia dialógica. Entretanto, os autores apresentam alguns pontos que merecem destaques neste artigo para pensar o cotidiano do/a professora/a e suas contribuições para o DPD, como a formação docente, o currículo, o ensino e a relação do professor (a) com o conhecimento.

Assim, Marcelo Garcia (1999) remete ao DPD como um processo de evolução e continuidade, envolvendo a prática, os conhecimentos e outros aspectos. Ainda, para o autor (2009, p. 9), este, "que é individual e coletivo, deve se concretizar no local de trabalho do/a professor/a, envolver as experiências e o desenvolvimento de competências profissionais”. É nesse sentido da complexidade que o autor destaca que o DPD é um componente do sistema 
educativo que sofre pressão de várias instâncias, sejam elas oficiais, extraoficiais, profissionais e extraprofissionais. Isso exige uma responsabilidade enorme para analisar o DPD em cada momento histórico, avaliar a política educativa que o fundamenta (plano de carreira, salário, reformas etc), as condições da formação ofertada, o modelo curricular e sua implementação, a cultura organizacional dos centros educativos, as forças sociais (família dos/as alunos/as, associações e partidos), os/as professores/as como categoria individual e coletiva (MARCELO GARCIA, 1999). Destarte, o DPD sofre "influência individuais, políticas, sociais, econômicas e profissionais" (MARCELO GARCIA, 1999, p. 196).

Baseado nos estudos deste autor e de outros, Ferreira (2020) buscou caracterizar alguns elementos do DPD, conforme exposto na figura a seguir:

Figura 1: Perspectiva de representação do Desenvolvimento Profissional Docente

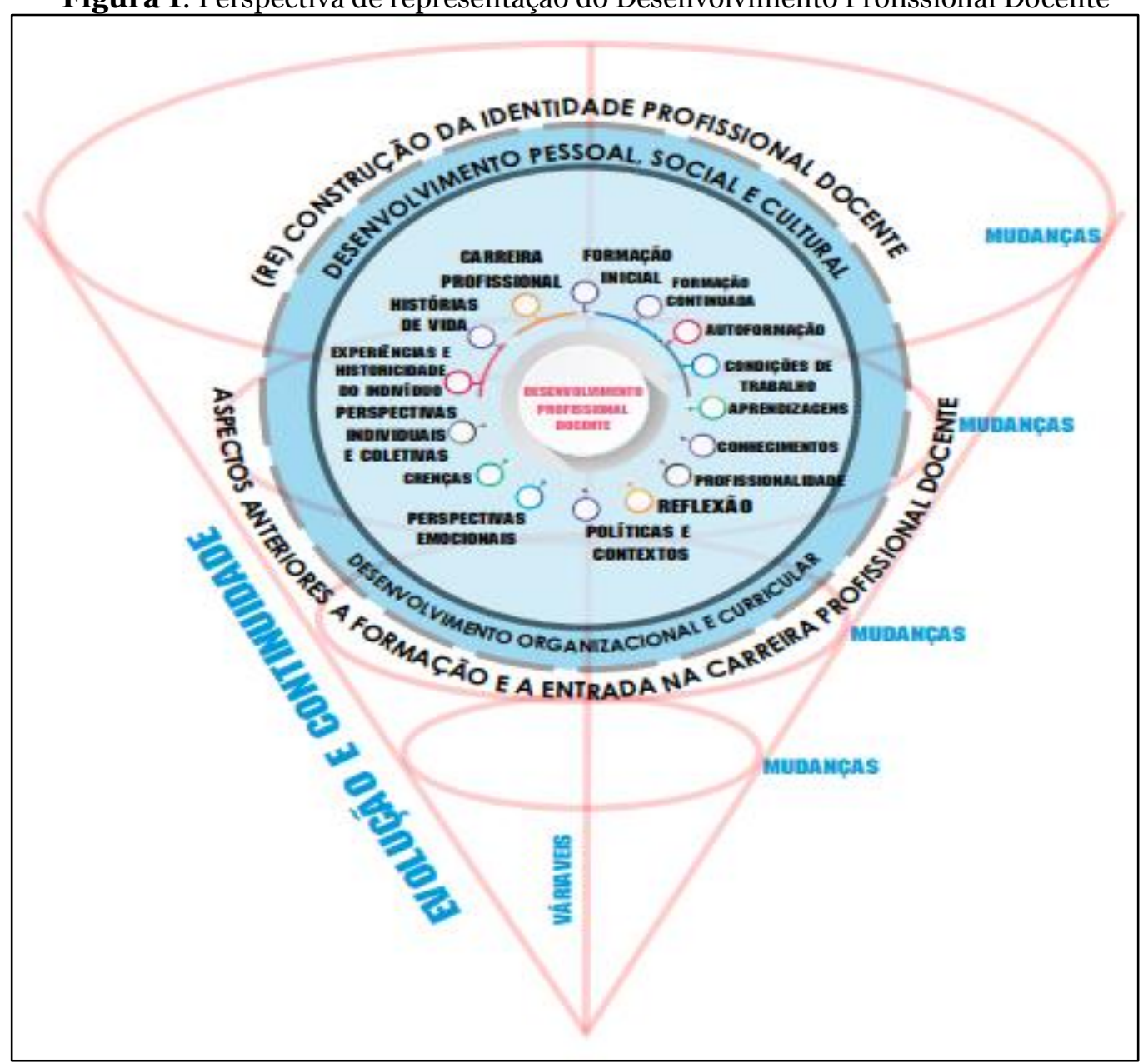

Fonte: Ferreira (2020).

A autora, em sua elaboração, consegue nos dar uma vista panorâmica do DPD, dos elementos que o envolvem, que o influenciam e pelos quais é influenciado, os vários contextos e desenvolvimentos que abrange. Desse modo, vimos o desenvolvimento pessoal, social, cultural, organizacional e curricular presentes, envolvidos e englobando aspectos anteriores e 
posteriores à entrada na profissão. De tal modo, é nesse processo que o cotidiano do professor é construído e colabora para construir a profissão.

\section{A formação docente e suas contribuições para o DPD}

A formação docente é o cerne do desenvolvimento profissional docente, de acordo os estudiosos desse campo de pesquisa (MARCELO GARCIA, 1999; DAY, 2001; MIZUKAMI, 1996; MUCHARREIRA, 2017). É na formação que geralmente o/a professor/a constrói e reflete a identidade docente e é no campo de atuação que essa identidade profissional sobressai.

Imbernón (2011) vê na formação o caminho da participação, reflexão, atualização científica, pedagógica e didática. Para o referido autor, a formação tem um papel primordial na vida do/da professor/a, para ajudá-lo/a na adaptação, no contexto de mudanças e incertezas que a educação se apresenta. Além disso, a formação também possibilita analisar as contradições da profissão docente e superar a alienação profissional (IMBERNÓN, 2011). Assim,

\footnotetext{
Isso implica, mediante a ruptura de tradições, inércias e ideologias impostas, formar o professor na mudança e para mudança por meio do desenvolvimento de capacidades reflexivas em grupo, e abrir caminho para uma verdadeira autonomia profissional compartilhada, já que a profissão docente deve compartilhar o conhecimento como o contexto. Isso implica uma mudança nos posicionamentos e nas relações com os profissionais, já que isolados eles se tornam mais vulneráveis no entorno político, econômico e social (IMBERNÓN, 2011, p. 15-16).
}

Diante deste contexto, Imbernón (2011) aponta que a formação docente deveria estimular algumas mudanças, como por exemplo, reconhecer que o/a professor/a é um ser singular, possui conhecimentos objetivos e subjetivos, que carece de respeito e aceitação; a aquisição do conhecimento por parte do/a professor/a é um processo amplo e não linear; o conhecimento é adquirido por ele/ela a partir da prática profissional e pelo contexto institucional que está inserido; é um processo complexo, adaptativo e experiencial.

Essa visão do autor traz algumas implicações para a formação, dentre elas avaliar o desenvolvimento curricular dos cursos de formação de professores, seus programas de disciplinas e prezar pela qualidade do ensino ofertado neles, por exemplo. Em decorrência disso, preconizamos que deve ser garantida uma formação docente contextualizada, democrática, dialógica, autônoma, emancipatória, enfim, que respeite as diferentes formas de viver e aprender dos sujeitos.

Reconhecemos que ensinar não é uma tarefa fácil e traz algumas exigências e necessidades para quem ousa a entrar nessa "seara". Freire e Shor (2008, p.12) afirmam que o/a professor é sobrecarregado com "aula demais, aluno demais, e controle administrativo 
demais de tal modo que a necessidade de alguma coisa que funcione em classe é muito maior do que uma aparente necessidade de teoria”. Esta realidade provoca os/as docentes a optarem mais pelos aspectos práticos da educação do que para os teóricos.

A docência exige demais do/a professor/a, visto que se trata de tarefas complexas relativas às demandas da profissão. Portanto, para dar conta dessas exigências, o tempo é fator primordial. Há carência de tempo para se dedicar ao crescimento profissional, tempo para pesquisar, para buscar formação continuada, planejar aulas. Além disso, necessita de um local de trabalho que tenha infraestrutura adequada, remuneração digna, plano de carreira, recursos pedagógicos, didáticos e tecnológicos.

A formação permanente, assim chamada por Paulo Freire, possibilita o crescimento profissional. Vejamos:

Os professores deveriam ter nas mãos, através das próprias organizações, não só a defesa de seus salários, mas também o direito de ter melhores condições para o trabalho educacional. Em segundo lugar, os professores precisam conquistar o direito de prosseguir sua formação. Os professores, cujo sonho é a transformação da sociedade, têm de ter nas mãos um processo permanente de formação, e não esperar do establishment a formação profissional. Quanto mais um educador tem consciência dessas coisas, mais aprende da prática, e então descobre que é possível trazer para dentro da sala de aula, dentro do contexto do seminário, momentos de prática social (FREIRE; SHOR, 2008, p.62).

A busca por uma formação permanente permite a reflexão sobre as condições de trabalho, o salário, a necessidade de uma formação continuada para melhorar a prática pedagógica, o aperfeiçoamento dos conhecimentos, a oferta de um ensino dialógico, o favorecimento do desempenho dos/as alunos/as, ou seja, contribuir para uma educação emancipatória para todos/as envolvidos/as no processo do ensinar e do aprender.

Nessa mesma perspectiva, Mucharreira (2017) discorre em sua tese que a formação continuada estimula a reflexão e se configura como a mais recorrente e eficaz na promoção do DPD. O desenvolvimento profissional ocorre "à medida que os docentes ganham experiência, sabedoria e consciência profissional” (OLIVEIRA, 2016, p.49). O/a professor/a passa a ter consciência da precarização de sua profissão e o quanto isso o/a deixa mal preparado/a para enfrentar os desafios que o cotidiano escolar oferece (GATTI; BARRETO; ANDRÉ, 2011). Desse modo, desenvolver-se profissionalmente é também desenvolver-se cotidianamente, aprendendo com a/na prática e a experiência, instruindo-se com a formação e as lidas da vida pessoal, social e profissional.

Com isso, percebemos que o/a professor/a é um/a profissional com muitas limitações para desenvolvimento do seu próprio trabalho, pois 
Os professores têm poucas oportunidades de ver salas de aula libertadoras. Os programas de formação de professores são quase sempre tradicionais e as escolas que eles frequentam não estimulam a experimentação. Assim, o problema dos modelos é a primeira questão que os professores levantam. Parte desse problema envolve outras questões: Como a educação libertadora se diferencia da educação tradicional? Como se relaciona com a mudança social? (FREIRE; SHOR, 2008, p. 27).

Freire e Shor (2008) questionam como o profissional docente tem sido formado para o exercício de sua profissão, apresentam uma crítica aos modelos tradicionais da formação, pois estes se tornam referências para as futuras atuações profissionais. Os autores apontam que a formação docente exige aperfeiçoamento intelectual e cultural e que esse aperfeiçoamento acontece na prática, valorizando a formação permanente. A profissão docente requer do professor uma melhoria constante ao longo da sua carreira: "A educação tem a ver com um processo de formação permanente" (FREIRE; SHOR, 2008, p. 145). Ainda conforme os referidos autores:

Para que os professores se transformem, precisamos, antes de mais nada, entender o contexto social do ensino, e então perguntar como é que esse contexto distingue a educação libertadora dos métodos tradicionais. Retomemos aquele importante ponto que se tornou muito claro para mim, depois do Golpe: a educação não é, por si só, a alavanca da transformação revolucionária. O sistema escolar foi criado por forças políticas cujo centro de poder está distante da sala de aula. Se a educação não é a alavanca da transformação, como é que podemos compreender a educação libertadora? Quando você chega a esta dúvida, você deve parar e refletir de outro modo. A educação libertadora é, fundamentalmente, uma situação na qual tanto os professores como os alunos devem ser os que aprendem; devem ser os sujeitos cognitivos, apesar de serem diferentes. Este é, para mim, o primeiro teste da educação libertadora: que tanto os professores como os alunos sejam agentes críticos do ato de conhecer (FREIRE; SHOR, 2008, p. 46).

Temos nessa discussão alguns elementos que merecem destaques. Primeiro, que é preciso conhecer para intervir numa realidade. Segundo a ruptura do discurso que a educação é a única responsável pela transformação social. Terceiro, que não há neutralidade na educação, pois ela foi criada por forças políticas com uma intencionalidade. Quarto, uma educação para ser libertadora precisa envolver professores/as e alunos/as como agentes críticos e construtores de conhecimentos.

Esses pontos nos instigam a pensar sobre o DPD nesse processo. Esse considera a realidade (ou as realidades) onde o/a professor/a vive/atua e suas nuances; estas realidades constroem muitas das características do DPD, não sendo um processo estático, único e involuível, mas mutável; é participante do DPD, tanto de sua construção quanto de sua evolução, os vários contextos existentes com suas abordagens e seus propósitos; é individual e coletivo, e o aspecto social é componente de sua composição.

Ao adentrar no campo de discussão da formação, especificamente no campo do DPD, Imbernón (2011, p.7) aponta: 
Em suma, a profissão docente deve abandonar a concepção predominante no século XIX de mera transmissão do conhecimento acadêmico, de onde de fato provém, e que se tornou inteiramente obsoleta para a educação dos futuros cidadãos em uma sociedade democrática: plural, participativa, solidária e integradora [...].

O mundo mudou, as pessoas mudaram, as culturas se diversificaram cada vez mais e a escola precisa acompanhar todas essas transformações. A escola não pode negar a efetivar profundas mudanças no seu interior, tanto no campo da estrutura física quanto nas práticas pedagógicas, nas relações entre docentes e discentes. Imbernón (2011, p.9) aponta algumas mudanças que ocorreram nos últimos anos: "Uma evolução acelerada da sociedade em suas estruturas materiais, institucionais e formas de organização da convivência, modelos de família, de produção e distribuição, que têm reflexos na mudança inevitável das atuais formas de pensar, sentir e agir das novas gerações”.

As mudanças no cenário social precisam chegar na formação de professores/as e contribuir para o crescimento profissional docente na superação dos desafios que a educação dialógica apresenta - dar vozes a todos sujeitos que a compõem. Para que essa educação seja emancipatória, democrática, solidária, isto é, humanista, é necessário superar as desigualdades sociais.

Imbernón (2011) chama-nos a atenção para uma formação profissional docente alicerçada em "novas competências profissionais no quadro de um conhecimento pedagógico, científico e cultural revistos. Em outras palavras, a contemporaneidade requer um profissional diferente” (p.12). Freire e Shor já discutiam essas competências no final da década de 80 do século passado. Ira Shor questiona Paulo Freire sobre essas competências e ele responde que é necessário romper com a educação bancária, isto é, com a transferência de conhecimentos descontextualizados da realidade dos/as alunos/as; romper com o autoritarismo e dar lugar à autonomia na prática pedagógica; ofertar uma pedagogia dialógica no cotidiano da sala de aula; ter disciplina na busca pelo conhecimento; valorizar o conhecimento e história de vida dos/das alunos/as, entre outros aspectos.

Ira Shor aborda alguns temores que os/as professores/as apresentam quando vão em direção a essa transformação, dentre eles:

Temem perder o emprego por praticar a educação emancipadora, ao invés da pedagogia da transferência de conhecimento. Falam do risco que a utilização de uma ideologia de oposição causaria à sua carreira, se se envolvessem numa política de oposição dentro de suas instituições. Temem, também, o constrangimento de reaprender sua profissão diante dos estudantes. Os professores querem sentir-se experimentados; por isso, a necessidade de se recriar no trabalho intimida a muitos deles (FREIRE; SHOR, 2008, p.67). 
Uma formação docente política dará conta desses medos, segundo Freire, no diálogo com Shor. O referido autor afirma que o/a professor/a não pode viver refém dos medos, mas estabelecer limites para esses medos, para não o/a paralisar frente às adversidades que a profissão traz. É preciso ter ousadia para contrapor a ideologia dominante na sociedade (FREIRE; SHOR, 2008).

Outro ponto importante a ser destacado do livro "Medo e ousadia: o cotidiano do professor" é o discurso de Ira Shor:

O desgaste do professor e a resistência dos alunos fazem com que muitos professores se perguntem por que estão na educação. Não é um lugar para se tornar rico e famoso. O salário e o prestígio profissional caíram nos últimos quinze anos. Têm algumas condições favoráveis - férias longas, jornada de trabalho mais curta e o incentivo moral de trabalhar pelo desenvolvimento humano. Muitos professores ingressaram na profissão inspirados pelo bem que poderiam fazer, até mesmo como serviço público, buscando fazer com que seus estudantes experimentassem a alegria de aprender. Mas agora, mais do que nunca, os professores estão recebendo menos recompensas e mais dissabores um momento de crise na profissão que predispõe alguns professores aos sonhos libertadores (FREIRE; SHOR, 2008, p. 67).

Este discurso foi proferido há quase trinta anos, mas quando analisamos a partir do atual contexto educacional brasileiro, ele parece que acabou de ser escrito. Se avaliarmos a atual conjuntura, a partir das mudanças ocorridas nos últimos três anos, veremos que foi aprovado um conjunto de medidas que afetam a profissão docente, tais como: Emenda Constitucional n. ${ }^{\circ} 95$, que congela os gastos públicos por vinte anos, dentre eles os gastos com a educação (BRASIL, 2016); a proposta de projeto da Escola Sem Partido (Lei da Mordaça) (BRASIL, 2015), que criminaliza a atuação docente acusando os/as professores/as de "doutrinadores". Esses são os dissabores que os/as professores/as têm experimentado nos últimos anos, o que carece de estudos para avaliar os impactos dessas mudanças no DPD, pois os/as professores/as vêm sofrendo retaliações em sua autonomia, formação e prática docente.

Desse modo, o DPD envolve e abarca os vários contextos e sua avaliação não pode (nem deve) deixar de fora a atual conjuntura política em que vivemos, implementando políticas públicas e provocando mudanças devastadoras no âmbito social e profissional dos/as professores/as. Na perspectiva da formação, num âmbito mais específico, o currículo também vem sendo atingido e este será refletido na próxima seção.

\section{O currículo e suas contribuições para o DPD}

Baseado em Freire e Shor (2008), Ana Maria Saul afirma, no prefácio do livro, que o currículo, numa perspectiva libertadora, para contribuir com o DPD, precisa desempenhar o papel de "desocultar a ideologia dominante" (SAUL, 2008, p. 8). Dessa forma, a proposta é de desfazer a forma como o currículo é disseminado atualmente. Há uma propagação em massa 
da ideologia dominante que vem sendo tomada como padrão para formular os modelos de currículo. Sacristan (2000, 2013), Young (2000, 2007, 2011, 2014, 2016), Apple (2006), entre outros, denunciam que o currículo, ao invés de desocultar as reais relações existentes entre conhecimento e sociedade, como está construído de maneira vertical e prescrita, tem contribuído para escondê-las. Dessa forma, um currículo "libertador" exige desconstruções.

Para Freire e Shor (2008), o currículo padrão é um dos responsáveis pela evasão escolar, uma vez que ele aliena os/as estudantes, propõe uma pedagogia da repetição e provoca a desmotivação no ato de aprender. "O currículo passivo baseado em aulas expositivas não é somente uma prática pedagógica pobre. É o modelo de ensino mais compatível com a promoção da autoridade dominante na sociedade e com a desativação da potencialidade criativa dos alunos" (p.21). Este modelo de currículo não favorece os/as alunos/as, tampouco o desenvolvimento profissional dos/as professores/as, os quais acabam se tornando mero executores de tarefas prontas.

Marcelo Garcia (1999) nos mostra vários modelos de DPD, dentre eles está o modelo baseado no desenvolvimento curricular e sua implementação. Ele afirma que este modelo é um instrumento que pode favorecer o desenvolvimento docente, já que exige do/a professor/a engajamento individual e coletivo, bem como a busca por uma formação permanente e revisão de seus conhecimentos, além de exigir informações sobre as inovações curriculares que irá trabalhar no cotidiano. Isso coloca o/a docente em constante busca pelo aperfeiçoamento profissional, pois ele/ela terá que se envolver com a elaboração e execução curricular de forma crítica.

Freire e Shor (2008) vão além, visto que acreditam que não só o/a professor/a deve se envolver com o currículo, mas também os/as alunos/as. Um caminho apontado por eles é o trabalho a partir da pesquisa, porque "ele educa o professor a projetar um currículo intrinsecamente motivador. Também diminui a distância profissional entre o professor e os alunos" (p. 21). Os autores acreditam que a partir dessa dialogicidade no ato de ensinar, professor e alunos aprendem juntos, todos ganham em termos de conhecimento e relações afetivas.

A educação é muito mais controlável quando o professor segue o currículo padrão e os estudantes atuam como se só as palavras do professor contassem. Se os professores ou os alunos exercessem o poder de produzir conhecimento em classe, estariam então reafirmando seu poder de refazer a sociedade. A estrutura do conhecimento oficial é também a estrutura da autoridade social. E por isso que predominam o programa, as bibliografias e as aulas expositivas como formas educacionais para conter os professores e os alunos nos limites do consenso oficial. O currículo passivo baseado em aulas expositivas não é somente uma prática pedagógica pobre. E o modelo de ensino mais compatível com a promoção da autoridade dominante na sociedade e com a desativação da potencialidade criativa dos alunos. (FREIRE; SHOR, 2008, p.21) 
O currículo aqui é apresentado pelos autores como um instrumento de controle da educação e o/a docente é sujeito passivo que está na ordem desse controle social. Mas os/as alunos/as e professores/as têm o poder de subverter esse lugar de passivos e assumir a condição de ativos na produção do conhecimento na sala de aula. É nessa subversão que todos os sujeitos que constituem a escola rompem com uma prática pobre para assumir as potências criativas que impulsionam o DPD e a aprendizagem dos/as alunos/as.

Ainda conforme os referidos autores, é preciso romper com a visão de um currículo neutro: "Esses currículos falsamente neutros formam os estudantes para observar as coisas sem julgá-las, ou para ver o mundo do ponto de vista do consenso oficial, para executar ordens sem questioná-las, como se a sociedade existente fosse fixa e perfeita" (FREIRE; SHOR, 2008, p.24). Freire e Shor (2008) propõem uma educação libertadora que seja capaz de construir uma consciência crítica nos/nas estudantes, para que estes/estas sejam capazes de analisar o contexto político e histórico em que estão inseridos e intervir nele. Assim, poderão contribuir para a recriação ou reconstrução da sociedade. A resistência estudantil é apresentada pelos autores como um caminho eficaz para ruptura de um currículo opressor.

No que concerne a participação do/a professor/a na elaboração do currículo, Freire e Shor (2008) apontam que os currículos vêm praticamente prontos, elaborados por autoridades escolares e pouco ou nenhum espaço é dado ao/à docente para participar de sua construção. Elaboram um currículo que é "até “à prova de professores"” (p. 96). Destarte, os/as professores/as perdem sua autonomia com as prescrições que apontam os caminhos do trabalho docente.

O controle estatal do currículo requer o reinado dos administradores e contadores que, então, necessitam de uma pedagogia quantificável para controlar o que os professores e alunos fazem em cada sala de aula. Essa hierarquia considera que a abordagem da transferência de conhecimento é a mais adequada à manutenção da autoridade. Essa corrente de autoridade termina nas escolas e universidades passivas, dominadas pela pedagogia de transferência, no País inteiro (FREIRE; SHOR, 2008, p.96).

Os referidos autores afirmam que a educação é um ato político e que o/a professor precisa assumir a politicidade da educação, bem como pensar o seu papel no rompimento com a pedagogia da repetição e alienação, para propor uma pedagogia libertadora, em que professores e alunos/as assumam um papel ativo na elaboração curricular. Quando o/a professor/a assume essa condição, seu desenvolvimento profissional é potencializado e sua prática pedagógica é alicerçada numa visão crítica da educação.

\section{O ensino e suas contribuições para o DPD}

Freire e Shor (2008, p.19) defendem que a educação deve provocar a integração entre docentes e discentes: 
A educação deve ser integradora - integrando os estudantes e os professores numa criação e recriação do conhecimento comumente partilhadas. $\mathrm{O}$ conhecimento, atualmente, é produzido longe das salas de aula, por pesquisadores, acadêmicos, escritores de livros didáticos e comissões oficiais de currículo, mas não é criado e recriado pelos estudantes e pelos professores nas salas de aula.

A relação dialógica, quando estabelecida entre professor/a e alunos/as, contribui para construção do conhecimento de forma prazerosa e significativa. As aulas configuram-se como um momento de compartilhamento de conhecimentos, em que todos envolvidos se desenvolvem numa relação de respeito mútuo. Uma educação democrática e participativa exige do professor um ensino também democrático e participativo (FREIRE; SHOR, 2008). Destarte,

O ambiente verbal da sala de aula é uma chave. Permite que os alunos saibam se esta aula vai ser a mesma coisa que as aulas alienantes do passado, ou se é possível uma abertura criativa. Uma fala profissional imponente convalida suas culturas do silêncio ou da sabotagem (FREIRE; SHOR, 2008, p. 173).

Quando o/a professor/a se propõe a adotar uma prática pedagógica dialógica, ele/ela cresce, pois abrir para o diálogo requer uma busca constante pelo conhecimento e um planejamento inovador. Neste contexto, o/a docente será um profissional pesquisador, aquele/a que assume uma postura de formação continuada constante.

Nas palavras de Freire e Shor (2008, p. 17):

Procuro usar exercícios que ao mesmo tempo me eduquem e eduquem os estudantes: leituras breves, redações, experiências de debates e reflexão, e mantenho meus planos de curso limitados e frouxos. Faço um voo sem instrumentos, muitas vezes sem um planejamento completo do curso ou uma lista de leituras que deem a segurança de uma ordem com a qual estou familiarizado. Quero aprender com eles quais seus verdadeiros níveis cognitivos e afetivos, como é sua linguagem autêntica, que grau de alienação trazem para o estudo crítico e quais suas condições de vida, como fundamentos para o diálogo e o questionamento.

O ato de ensinar traz essas possibilidades para o/a professor/a e, consequentemente, essa ação colabora com o seu desenvolvimento profissional e pessoal. Na sala de aula, o/a professor/a aprende a ser ético/a, paciente, compreensivo/a, respeitoso/a com ele/ela próprio e com seus/suas alunos/as. Aprende que cada um se desenvolve no seu ritmo, inclusive ele/ela. Ensinar exige um trabalho coletivo, troca de conhecimento, ousadia para romper com os modelos educacionais tradicionais que não somam na formação dos/das discentes e tampouco na própria formação docente (FREIRE; SHOR, 2008).

O/a professor/a pode e deve reinventar o conhecimento na sua ação educativa. Uma educação emancipatória possibilita isso, ou seja, produzir um conhecimento divergente do que 
vem tradicionalmente sendo "transferidos" nas escolas. Freire e Shor (2008) afirmam que essa prática causará estranheza, porquanto os/as estudantes estão acostumados com a mera transmissão do conhecimento. "Os estudantes não acreditam num professor libertador que não lhes empurre o conhecimento goela abaixo" (FREIRE; SHOR, 2008, p.22). Diante deste contexto, o/a professor/a precisará de um trabalho intelectual intenso para modificar as bases tradicionais da educação que são pautadas na repetição do conhecimento acabado. Assim sendo:

É importante aprender através da realidade, porém mais do que "ir até a realidade", você aceitou seus alunos trabalhadores como professores seus. Isso acrescenta profundidade ao conhecimento pela experiência, que é uma idéia comum na educação progressiva. O professor aprende dos alunos, e o professor universitário é informalmente educado pelos trabalhadores. Esse programa é diferente do currículo tradicional e mais democrático do que o ensino centrado no aluno (FREIRE; SHOR, 2008, p. 42).

A partir desse princípio, pensar em ensino, seja nas escolas da educação básica ou nas universidades, requer abandonar o modelo de formação tecnicista, desenvolvida por meio de um emaranhado de informações tradicionais (científicas, didáticas e pedagógicas), para então adotar uma construção de conhecimento e de valores a partir da reflexão crítica sobre a prática docente, do ganho mútuo da relação professor-aluno e, principalmente, do contexto social do ensino.

O ensino é parte essencial do DPD, é a tarefa mais conhecida e ainda a mais complexa que é desenvolvida pelo/a professor/a, pois envolve vários sujeitos na construção do processo de ensinar, que é também o processo de aprender. Ensino é relação, é construção, é possibilidade de mudanças. Marcelo Garcia (2009, p. 9) ponta que "a denominação desenvolvimento profissional se adequa melhor à concepção do professor enquanto profissional do ensino". O/a professor/a é esse profissional do ensino que se desenvolve profissionalmente na relação, desempenhando suas atividades laborais.

\section{A relação do professor/a com o conhecimento}

De acordo Freire e Shor (2008), existe um problema na busca pelo conhecimento por parte dos/as docentes. Segundo os referidos autores, os/as professores/as não dispõem de tempo para estudar. Daí que surge o interesse dos/as professores/as mais por práticas do que por teorias, porque veem nas práticas uma funcionalidade. Para os Freire e Shor (2008), aí reside um sério problema, pois a teoria precisa se fazer presente no cotidiano escolar. E outra questão sobre isso reside no fato de, dessa forma, haver separação entre teoria-prática, como se cada uma delas existisse sozinha. Essa perspectiva de olhar é oriunda da forma como esse conhecimento é construído e desenvolvido. Do mesmo modo, a formação docente inicial e 
continuada deve provocar o reconhecimento da importância da relação teoria-prática para a sala de aula e incentivar o/a professor/a a buscar condições favoráveis para obter essas conquistas.

No diálogo entre os autores, Shor apresenta outro problema, que ele vai denominar de "hierarquia política do conhecimento":

\begin{abstract}
Determinado tipo de conhecimento é mais valorizado do que outro. Certos tipos de conhecimento não conseguem ter reconhecido seu valor, a menos que assumam forma tradicional dentro desta ou daquela disciplina. Por exemplo, a tecnologia, para as grandes empresas e para as Forças Armadas, é mais importante do que as Ciências Humanas. A pesquisa de interesse empresarial conta com recursos muito fartos, enquanto que os estudos sobre socialismo são marginalizados. Além disso, o conhecimento produzido dentro da universidade é mais considerado do que o conhecimento produzido por cientistas autônomos fora da universidade (FREIRE; SHOR, 2008, p.20).
\end{abstract}

Essa problemática poderá ser resolvida a partir de uma relação positiva entre o/a professor/a e o conhecimento para romper com os obstáculos epistemológicos surgidas no decorrer da prática docente. Os questionamentos deverão sempre estar presentes no momento de privilegiar determinados conteúdos e didáticas em detrimentos de outros, ou determinadas culturas em detrimento de outras.

Os autores apresentam dois ciclos do conhecimento que se relacionam dialeticamente, o primeiro consiste no conhecimento novo; e o segundo, num já existente. $\mathrm{O}$ problema, segundo eles, é que dicotomizamos esses momentos, isolando um conhecimento do outro. Quando o/a professor/a consegue valorizar esses ciclos do conhecimento, ele/ela se desenvolve profissionalmente, uma vez que "algumas dessas qualidades são, por exemplo, a ação, a reflexão crítica, a curiosidade, o questionamento exigente, a inquietação, a incerteza todas estas virtudes são indispensáveis ao sujeito cognoscente!” (FREIRE, SHOR, 2008, p. 18).

Nessa mesma perspectiva, Freire e Shor (2008) nos chama a atenção para o fato de que os conhecimentos dos conteúdos das disciplinas que os/professores/as lecionam são fontes que colaboram para o desenvolvimento docente. A relação com o conhecimento traz um potencial de criatividade para o/a docente e também possibilita recompensas no seu desenvolvimento profissional.

\title{
Considerações finais
}

A obra "Medo e ousadia: o cotidiano do professor" apresenta reflexões e problematizações que estão diretamente ligadas ao desenvolvimento profissional docente. Ao apresentar reflexões sobre um ensino humanizado e dialógico, traz concepções sobre o papel dos educadores libertadores, os temores e riscos dessa transformação e aponta o/a professor/a como protagonista da educação, consequentemente, do seu DPD. 
A profissão professor adquiriu novas características para responder as novas demandas da sociedade. Desta forma, para que o processo de formação inicial e continuada possa contemplar as demandas da profissão docente, é necessária uma verdadeira revolução nas estruturas institucionais formativas, relacionada aos currículos para os cursos de formações específicas, assim como na consolidação dos valores imprescindíveis para uma prática mais humana, consciente e dialógica dos professores em sala de aula.

O DPD não se dá apenas em processo de formação, mas também é movido por questões pessoais-profissionais, assim como as disposições do momento. Todos esses fatores irão condicionar as necessidades particulares e a forma como estas podem ser identificadas, visto que influenciam de maneira direta na prática docente.

Portanto, apesar de termos limitado essas reflexões a apenas uma obra, constatamos que Paulo Freire (em todos os seus estudos e obras) contribui muito e de maneira fundamental para os estudos sobre o DPD, apontando possíveis caminhos para a evolução e continuidade desse processo de desenvolvimento.

Diante da atual conjuntura política brasileira, materializar e reinventar Paulo Freire não é uma tarefa fácil, porém é necessária! A formação permanente com base em princípios políticos, como propõe Freire, possibilitará um rompimento de paradigmas acerca da neutralidade sobre a educação, possibilitando, deste modo, diversos caminhos para o DPD.

\section{Referências}

APPLE, M W. Ideologia e currículo. 3. ed. Porto Alegre: Artmed, 2006.

BRASIL, República Federativa. Emenda Constitucional n.o 95. 2016. Disponível em: http://www.planalto.gov.br/ccivil_03/constituicao/emendas/emc/emc95.htm. Acessado 07/05/20.

. Proposta de Projeto de Lei: Escola Sem Partido. 2015. Disponível em: http://www.camara.gov.br/sileg/integras/1317168.pdf. Acessado 24/12/19.

DAY, C. Desenvolvimento Profissional de professores: os desafios da aprendizagem permanente. Porto: Porto, 2001.

FERREIRA, L G. Desenvolvimento Profissional Docente: percursos teóricos, perspectivas e (des)continuidades. (no prelo). 2020.

FREIRE, P. Política e educação. Indaiatuba: Villa das Letras Editora, 1993a.

. Professora sim tia não: cartas a quem ousa ensinar. São Paulo: Paz e Terra, 1993b.

Pedagogia da autonomia: saberes necessários à prática educativa. 22a.ed.

São Paulo: Paz e Terra, 1996.

A educação na cidade. São Paulo: Editora Cortez, 2001. 
FREIRE, P; SHOR, I. Medo e Ousadia: o cotidiano do professor. Rio de Janeiro: Paz e Terra. 12 ed. 2008.

GATTI, B A; BARRETO, E S S; ANDRÉ, M E.D.A. Políticas docentes no Brasil: um estado da arte. Brasília: UNESCO. 2011.

IMBERNÓN, F. Formação docente e profissional: forma-se para a mudança e a incerteza. 9. ed. São Paulo: Cortez, 2011.

MARCELO GARCIA, Carlos. Formação de professores: para uma mudança educativa. Porto, PT: Porto Editora, 1999.

Desenvolvimento Profissional: passado e futuro. Sísifo - Revista das

Ciências da Educação, n. 8, jan./abr. 2009, p. 7-22.

MIZUKAMI, M das G. Docência, Trajetórias Pessoais e Desenvolvimento Profissional. In:

REALI, Aline Maria de Medeiros Rodrigues \& MIZUKAMI, Maria das Graças

Nicoletti. (Org.). Formação de Professores: tendências atuais. São Carlos: EDUFSCar,1996.

MUCHARREIRA, P dos S R. O papel da formação contínua centrada na escola, na (re)construção do projeto educativo e no desenvolvimento profissional docente: um estudo de caso. 2017, 416f. Tese (Doutorado em Educação).

Universidade de Lisboa, Lisboa, 2017.

OLIVEIRA, I P de A. "Entrei no curso assim, eu... e hoje, nesse grupo, eu me sinto nós": a formação de professores no curso vivências com a musicalização.

Dissertação (Mestrado Profissional em Artes). Universidade de Brasília. Brasília, 2016.

SACRISTÁN, J G. Currículo: uma reflexão sobre a prática. 3 ed. Porto Alegre: Artmed. 2000.

Saberes e incertezas sobre o currículo. Tradução Alexandre Salvaterra; revisão técnica Miguel González Arroyo. Porto Alegre: Penso, 2013.

SAUL, A M. Prefácio. In: FREIRE, Paulo; SHOR, Ira. Medo e Ousadia: o cotidiano do Professor. Rio de Janeiro: Paz e Terra.12 ed. 2008. p. 7-8.

YOUNG, M. O currículo do futuro: da "nova sociologia da educação" a uma teoria crítica do aprendizado. Campinas: Papirus, 2000.

. Para que servem as escolas? Educação e Sociedade., vol. 28, n. 101. Campinas: set./dez. 2007.

O futuro da educação em uma sociedade do conhecimento: o argumento radical em defesa de um currículo centrado em disciplinas. Revista Brasileira de Educação, v. 16 n. 48, set./dez. 2011.

. Teoria do currículo: o que é e porque é importante. Cadernos de Pesquisa. V. 44, $\mathrm{n}^{\mathrm{o}} .51$, p. 190-202, jan./mar. 2014. 
Por que o conhecimento é importante para as escolas do século XXI? Cadernos de Pesquisa, v. 46, n.159, p. 18-37 jan/mar. 2016.

\section{Biografia Resumida}

Lilian Moreira Cruz: Doutoranda em Educação pela Universidade Federal da Bahia (UFBA), Mestra em Educação em Ciências e Matemática pela Universidade Estadual do Sudoeste da Bahia (UESB), Professora assistente da Universidade Estadual de Santa Cruz (UESC). Grupo de Estudos e Pesquisas em Educação Infantil/UESC.

Lattes: http://lattes.cnpq.br/5600692150509688

Contato:lmcruz@uesc.br

Andréia Cristina Freitas Barreto: Doutoranda em Educação pela Universidade Federal da Bahia (UFBA), Mestra em Educação em Ciências pela Universidade Estadual de Santa Cruz (UESC), Professora substituta da Universidade Estadual da Bahia (UNEB).

Lattes: http://lattes.cnpq.br/3620217817854224

Contato: andreyafreitas@hotmail.com

Lúcia Gracia Ferreira: Doutora em Educação pela Universidade Federal de São Carlos (UFSCar). Pós-doutorado pela Universidade Federal da Bahia (UFBA) e Universidade Estadual do Sudoeste da Bahia (UESB). Professora da Universidade Federal do Recôncavo da Bahia (UFRB) e da Universidade Estadual do Sudoeste da Bahia-Itapetinga (UESB). Professora do Programa de Pós-Graduação em Educação da Universidade Federal da Bahia; Grupo de Pesquisa e Estudos Pedagógicos/UESB e Docência, Currículo e Formação/UFRB

Lattes: http://lattes.cnpq.br/2208995326703695

Contato: luciagferreira@ufrb.edu.br 